\title{
17
}

\section{An Equivalent Rainfall Technique to Identify Dry Weather Flow Data for City of Detroit Flow Balance Analysis}

Andrew Santini, Philip Brink, Ben Sherman, and Mark TenBroek

Flow data collected from over twenty metered sites in Detroit, Michigan are used to determine the source of flows from districts tributary to the Detroit Water \& Sewerage Department (DWSD) collection system through a flow balance analysis. Criteria developed for selecting data include precipitation, snowmelt, and basin dewatering. The Greater Detroit Regional Sewer System (GDRSS) model, a hydraulic and hydrologic model of Detroit's sewer collection system, was used to refine the rainfall-based criteria. Specifically, it was used to determine the time required for the system to return to dry weather flow (DWF) conditions after one or a series of rainfall events. As a result of model simulations, relationships were developed to represent time-to-dry as a function of the rainfall amount of single- or multiple-day rainfall events. These relationships are a key component of the overall data selection for the flow balance, and provide an objective approach to characterizing DWF in the DWSD collection system.

\subsection{Introduction}

This chapter describes the simulations that were evaluated with the GDRSS model for support of the flow balance analysis. Flow data are being collected at a number of sites throughout the system, shown in Figure 17.1, for use in the analysis to determine flows for the various incremental areas.

Santini, A., P. Brink, B.J. Sherman and M.J. TenBroek. 2001. "An Equivalent Rainfall Technique to Identify Dry Weather Flow Data for City of Detroit Flow Balance Analysis." Journal of Water Management Modeling R207-17. doi: 10.14796/JWMM.R207-17.

(C) CHI 2001 www.chijournal.org ISSN: 2292-6062 (Formerly in Models and applications to Urban Water Systems. ISBN: 0-9683681-4-X) 


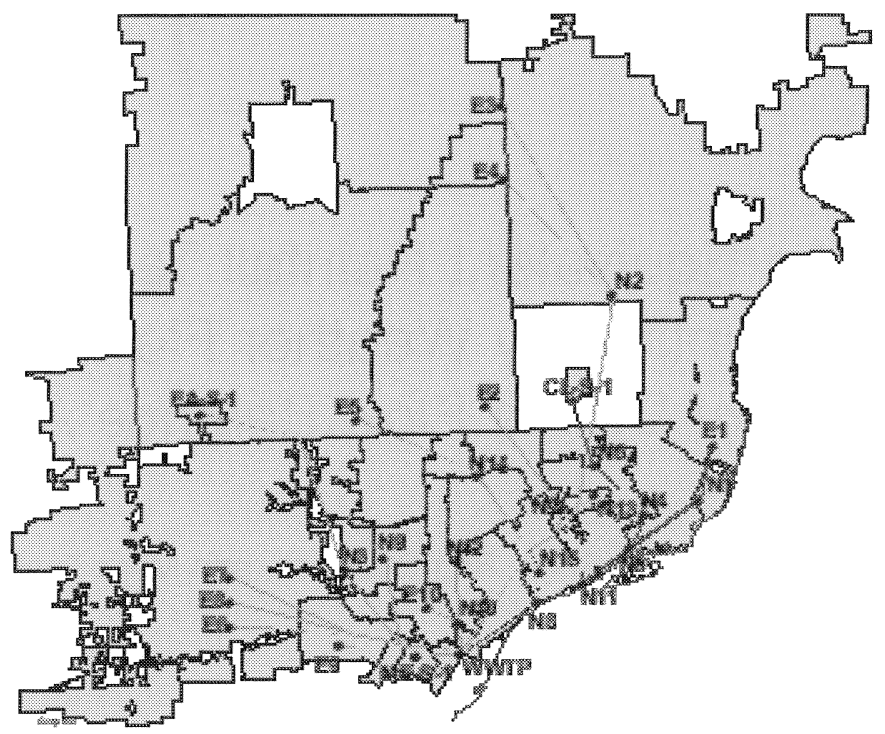

Figure 17.1 Meter connectivity diagram.

Flow balance results are being used for such purposes as identifying collection system metering problems, cost allocation, support planning, hydraulic and hydrologic analyses, and the identification of key system rehabilitation needs.

The flow balance equation for an incremental area can be expressed as follows:

$$
Q_{\text {incremental }}=Q_{\text {downstream }}-Q_{\text {upstream }}+\frac{\Delta V}{t}
$$

where:

$$
\begin{aligned}
Q & =\text { the volume of flow for a given time interval, } \\
\Delta V & =\text { the change in volume of in-system storage (ISS), and } \\
t & =\text { the time interval. }
\end{aligned}
$$

Detroit's portion of the collection system includes some 78 combined sewer overflow outfalls, which currently are not metered. To correctly calculate flows for an incremental area, a no-overflow condition must exist to maintain a mass balance in the flows. As long as no flows are lost from the system due to overflows, a flow-balance calculation can be made.

The rainfall selection criteria were initially based on the amount of rainfall that occurred on the current day and one preceding day. These criteria were 
subjectively set based on review of existing data and knowledge of the system; subsequently, the criteria did not work well under certain conditions. To refine these criteria, the GDRSS model was used to evaluate the system responses to various single- and multiple-day wet weather events to determine the time that would be required for the system to return to DWF conditions. In addition, the model was used to assess the impact of travel time and storage on calculating flows for the incremental tributary areas.

\subsection{Approach}

\subsubsection{Model Configuration}

The Greater Detroit Regional Sewer System (GDRSS) model was developed and calibrated for the purpose of evaluating the collection system for the city of Detroit and suburban areas for both current conditions and for planned improvements, including the improvements expected with the implementation of the city's Long-Term CSO Control Plan (LT CSO CP) (Detroit, 1996). The 1998 baseline version of the GDRSS model was used for the criteria simulations as this model most closely matches the conditions for which the flow data are being collected.

The GDRSS model is based on the EPA SWMM model (Huber, 1988). The SWMM RUNOFF component of the model is used to simulate the hydrology for all the simulations performed. Local collection system routing is also included in this model through the use of routing channels developed for this project. Results for the criteria selection assume that these empirical routing channels will adequately approximate the real system routing and duration of flows (TenBroek, 1999).

The SWMM EXTRAN model routes the flows generated by RUNOFF for specific storm events through the collection system. The EXTRAN model was used to provide estimates of overflows and treated flows resulting from specific events. The EXTRAN model includes the base wastewater or DWF, which can be adjusted to reflect seasonal changes (TenBroek, 1999). The simulations were performed for the month of April, which represents the highest DWF month. April is also part of the dormant season defined for rain-dependant inflow and infiltration (RDI/I) response, which is the higher response season. To review the impact of seasonal variation in the DWF estimates and RDI/I response, the simulations included two other months for comparison. The model was configured for June and October months to cover an average and low DWF month, respectively, and to cover low and average I/I response months, respectively. 
The current criteria assumes that not only will the model provide reasonable overflow and treated volumes for which the model was calibrated, but that it will also provide reasonable representation of the duration of wet weather flows.

\subsubsection{Storm Events Reviewed}

The criteria simulations were performed for single and multiple storm events of various sizes ranging from 0.1 -inch to 4 -inches. The multiple events consist of rainfall occurring for 4 days to review the impacts of cumulative rainfall. The events reviewed are provided in Table 17.1.

Table 17.1 Storm events reviewed.

\begin{tabular}{|c|c|c|c|c|c|c|c|c|c|c|}
\hline \multicolumn{11}{|c|}{ Single Storm Events Reviewed (measurement in inches) } \\
\hline Vol/d & 0.1 & 0.2 & 0.3 & 0.4 & 0.6 & 0.8 & 1.0 & 1.5 & 2.0 & 3.0 \\
\hline $\begin{array}{l}\text { Total } \\
\text { Rainfall }\end{array}$ & 0.1 & 0.2 & 0.3 & 0.4 & 0.6 & 0.8 & 1.0 & 1.5 & 2.0 & 3.0 \\
\hline \multicolumn{11}{|c|}{ Four-Day Storm Events Reviewed (measurement in inches) } \\
\hline Vol./d & 0.06 & 0.1 & 0.2 & 0.3 & 0.4 & 0.6 & 0.8 & 1.0 & & \\
\hline $\begin{array}{l}\text { Total } \\
\text { Rainfall }\end{array}$ & 0.24 & 0.4 & 0.8 & 1.2 & 1.6 & 2.4 & 3.2 & 4.0 & & \\
\hline
\end{tabular}

For each simulation, rainfall is assumed to be uniform over the entire tributary area. Also, rainfall volumes are applied uniformly over a 1 -h increment and are applied at hour 23 of the day. Having the rainfall occur during the last hour of the day provides the worst-case scenario for determining the number of days that must elapse before the system returns to DWF conditions. The distribution and volume of single and multiple storm events for a 1-inch (254 $\mathrm{mm}$ ) volume is shown in Figures 17.2a and 17.2b, respectively.

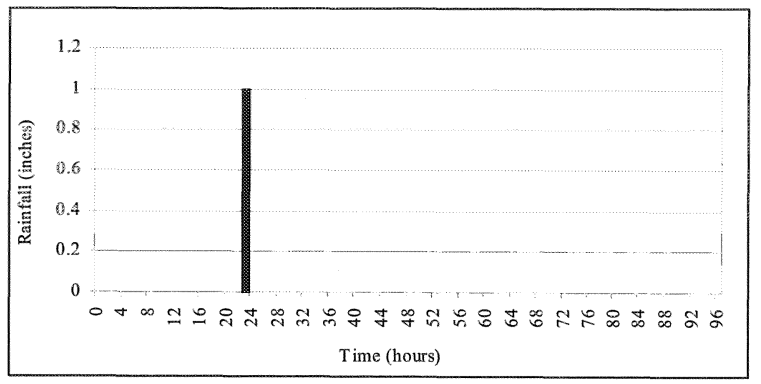

Figure 17.2a Single-day storm event distribution. 


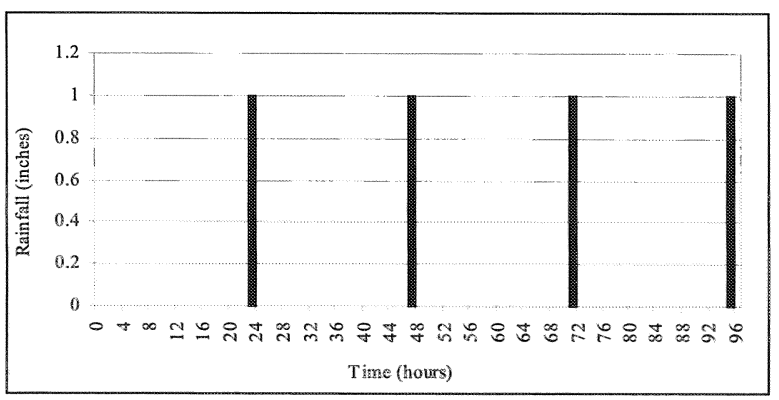

Figure 17.2b Multiple-day storm event distribution.

As real events are rarely uniform over the entire tributary area, especially one the size of the GDRSS area, the selection criteria will be based on review of approximately 40 rain gages throughout the system. Of these approximately 40 gages, an average of the five largest gage records is used for the precipitation on the day considered. This approach requires the assumption that the average of the actual event will be comparable to a simulated uniform event.

\subsubsection{Hydrologic Parameters}

The hydrologic parameters were modified in the model to account for various antecedent conditions. For these simulations, the initial values used are provided in Table 17.2; these represent average to wet antecedent conditions.

Table 17.2 Hydrologic parameter values.

\begin{tabular}{ll}
\hline Parameter & Value \\
\hline Impervious Depression Storage (inch) & 0.06 \\
Pervious Depression Storage (inch) & 0.29 \\
Initial Infiltration (inch per hour) & 0.83 \\
Minimum Infiltration (inch per hour) & 0.25 \\
\hline
\end{tabular}

To review the impact of the initial infiltration value on the results, the analysis includes simulations where the value for this parameter is allowed to vary. Full-scale sensitivity is not intended as part of the current analysis; rather, the intent is to determine qualitatively the impact that the selected value for infiltration has on the results for the current simulations. 


\subsubsection{Travel Time Impact}

The flow balance analysis assumes that travel time of the flows between the meters will not impact the flows calculated for a given increment. Whether travel time could impact the flow balance depends on the time interval relative to the flow balance analysis time interval, which is a 24-h period. As long as the travel time between any given pair of meters is much less than $24 \mathrm{~h}$, the potential to cause an error in the calculation of an incremental flow would be greatly reduced. Furthermore, provided the flows evaluated exhibit consistent trends, such as that for typical DWF diurnals, the potential for error would be further reduced.

The GDRSS model was used to simulate DWF conditions for both April, the highest DWF month, and October, the lowest DWF month. The model

Table 17.3 Travel time between meters.

\begin{tabular}{|c|c|c|c|c|c|}
\hline \multirow[t]{2}{*}{ Flow Path } & \multirow{2}{*}{$\begin{array}{l}\text { Path } \\
\text { Length } \\
\text { (miles) }\end{array}$} & \multicolumn{2}{|c|}{ Average Velocity (fps) } & \multicolumn{2}{|c|}{ Travel Time (hrs) } \\
\hline & & April & October & April & October \\
\hline $\mathrm{C} 1-\mathrm{S}$ to $\mathrm{N} 6$ & 0.07 & 3.07 & 2.96 & 0.03 & 0.04 \\
\hline E1 to N1 & 3.31 & 2.87 & 2.84 & 1.75 & 1.76 \\
\hline E2 to N7 & 5.72 & 3.83 & 3.78 & 2.33 & 2.36 \\
\hline E3 to N2 & 20.00 & 4.07 & 4.09 & 7.21 & 7.17 \\
\hline E4 to N2 & 18.00 & 4.07 & 4.09 & 6.49 & 6.45 \\
\hline $\mathrm{E} 5$ to $\mathrm{N} 14$ & 11.96 & 4.33 & 4.31 & 5.53 & 5.58 \\
\hline E6 to WWTP & 0.88 & 3.78 & 4.52 & 0.32 & 0.28 \\
\hline E7 to WWTP & 7.31 & 3.49 & 3.58 & 2.95 & 3.01 \\
\hline E8 to WWTP & 5.63 & 3.48 & 3.60 & 2.26 & 2.30 \\
\hline E9 to WWTP & 2.71 & 4.13 & 4.58 & 0.91 & 0.89 \\
\hline E10 to N10 & 0.73 & 4.08 & 4.96 & 0.24 & 0.21 \\
\hline $\mathrm{Fa}-\mathrm{S}-1$ to $\mathrm{N} 3$ & 8.24 & 2.87 & 2.81 & 4.08 & 4.15 \\
\hline MESI to WWTP & 2.71 & 4.13 & 4.58 & 0.91 & 0.89 \\
\hline N1 to N5 & 3.42 & 4.63 & 4.25 & 1.03 & 1.13 \\
\hline N2 to WWTP & 12.88 & 3.37 & 3.43 & 5.53 & 5.56 \\
\hline N3 to WWTP & 8.33 & 3.51 & 3.59 & 3.35 & 3.41 \\
\hline N4 to N5 & 2.07 & 4.01 & 3.78 & 0.66 & 0.72 \\
\hline N5 to N11 & 2.07 & 5.23 & 4.83 & 0.68 & 0.74 \\
\hline N6 to N4 & 5.14 & 3.64 & 3.53 & 2.62 & 2.69 \\
\hline $\mathrm{N} 7$ to $\mathrm{N} 11$ & 4.55 & 2.60 & 2.42 & 6.58 & 6.82 \\
\hline N7 to WWTP & 10.42 & 3.19 & 3.20 & 4.46 & 4.56 \\
\hline N8 to WWTP & 3.98 & 4.02 & 4.11 & 1.51 & 1.46 \\
\hline N9 to WWTP & 5.20 & 3.59 & 3.71 & 2.03 & 2.06 \\
\hline N10 to WWTP & 0.96 & 4.32 & 4.91 & 0.33 & 0.30 \\
\hline N11 to N8 & 1.63 & 4.65 & 4.35 & 0.51 & 0.55 \\
\hline N12 to N10 (along ET) & 4.98 & 3.03 & 3.03 & 2.56 & 2.56 \\
\hline N12 to N10 (along Lonyo) & 5.43 & 2.38 & 2.34 & 4.46 & 4.48 \\
\hline N13 to WWTP & 9.50 & 3.27 & 3.29 & 4.24 & 4.33 \\
\hline N14 to N15 & 0.78 & 2.09 & 2.07 & 0.33 & 0.33 \\
\hline N15 to N8 & 1.49 & 3.31 & 3.15 & 0.94 & 0.96 \\
\hline Average & 5.67 & 3.63 & 3.69 & 2.56 & 2.59 \\
\hline
\end{tabular}


provided computed flow velocities for all conduits and flow paths within the system. Given the conduit lengths and the velocities, the travel time for all of the flow paths were calculated. The result of this analysis is given in Table 17.3.

The average travel time for any given flow path between two meters is approximately $2.6 \mathrm{~h}$, or a $10.8 \%$ lag for a 24 -h analysis period. A 2.6 - $\mathrm{h} \mathrm{lag}$ could be significant under variable flow conditions, such as wet weather; however, because only DWF periods were evaluated, the meters measure similar flow conditions for the 24 -h period. Therefore, during DWF conditions, the impact of a $10.8 \%$ lag due to travel time on the flow balance calculations would be negligible.

\subsubsection{Change in In-System Storage Impact}

The flow balance analysis assumes that the last term in Equation 17.1, denoting change in the volume of the in-system storage (ISS) over time, is zero. During DWF conditions, the ISS may vary during the day due to diurnal flow changes, but on average, the total ISS at the end of the day would be expected to be the same as at the beginning of the day.

To confirm this assumption, the GDRSS model was used to determine the change in the ISS following a wet weather event for several flow paths. Results were reviewed for a 1-inch $(254 \mathrm{~mm})$, single rainfall event for a selected flow path. As can be seen in Table 17.4, the bias error is $6.3 \%$ for the second day following the event and $2.2 \%$ for the third day after the event.

The size of these errors continues to be diminished for each subsequent day until the system returns to DWF conditions. By the fourth day after the event, the error is $1 \%$ or lower, and the next day would be classified as a DWF day. The results of this analysis indicate that the change in the in-system storage

Table 17.4 Impact of change in ISS on incremental flow calculations results from 1-inch event for a selected meter flow path.

\begin{tabular}{|c|c|c|c|c|c|c|}
\hline \multicolumn{7}{|c|}{ Flow Path: N8 to WWTP } \\
\hline $\begin{array}{l}\text { Time } \\
\text { after } \\
\text { end of } \\
\text { storm } \\
\text { event }\end{array}$ & $\begin{array}{l}\text { Average } \\
\text { flow for } \\
\text { day at N8 }\end{array}$ & $\begin{array}{l}\text { Average } \\
\text { flow for } \\
\text { day in } \\
\text { DRI at } \\
\text { WWTP }\end{array}$ & $\begin{array}{l}\text { Average } \\
\text { incremental } \\
\text { flow }\end{array}$ & $\begin{array}{l}\text { ISS at end } \\
\text { of day }\end{array}$ & $\begin{array}{l}\text { Change in } \\
\text { ISS for } \\
\text { day }\end{array}$ & $\begin{array}{l}\text { Impact of } \\
\text { change in } \\
\text { ISS on } \\
\text { incremental } \\
\text { flow }\end{array}$ \\
\hline (Day) & (MGD) & (MGD) & (MGD) & (MG) & $\begin{array}{c}\text { (MG per } \\
\text { day) }\end{array}$ & (MGD) \\
\hline 1 & 373 & 483 & 109 & 19.64 & & \\
\hline 2 & 249 & 299 & 50 & 16.47 & -3.17 & $-6.3 \%$ \\
\hline 3 & 212 & 258 & 47 & 15.42 & -1.05 & $-2.2 \%$ \\
\hline 4 & 202 & 249 & 47 & 14.91 & -0.51 & $-1.1 \%$ \\
\hline 5 & 197 & 242 & 46 & 14.84 & -0.07 & $-0.2 \%$ \\
\hline
\end{tabular}


volume is insignificant for days that would be classified as a DWF day. Because the results of this analysis indicate the change in the storage volume can cause significant bias error in the flow balance analysis, it is imperative that only DWF data be included in the flow balance analysis.

\subsection{Criteria Simulation Results}

\subsubsection{Single and Multiple Events}

Flows at the Detroit WWTP and at several key locations within the system were reviewed for determining the time elapsed before the system returned to DWF conditions. The duration of the recession back to DWF conditions at the plant was determined for the time for the flows to return to within $2 \%$ of the base DWF rates.

The results, in terms of the time required for the system to return to DWF conditions, are provided in Figure 17.3. For single events, the time to return to DWF conditions range from less than $1 \mathrm{~d}$ for a 0.1 -inch $(2.5 \mathrm{~mm})$ event to just over $4 \mathrm{~d}$ for a 3.0 -inch $(76.2 \mathrm{~mm})$ event. For multiple events, the time for the system to recover ranged from a fraction of a day for the 0.06-inch $(1.5 \mathrm{~mm})$ per day event to over $3 \mathrm{~d}$ for the 1.0 -inch $(25.4 \mathrm{~mm})$ per day event.

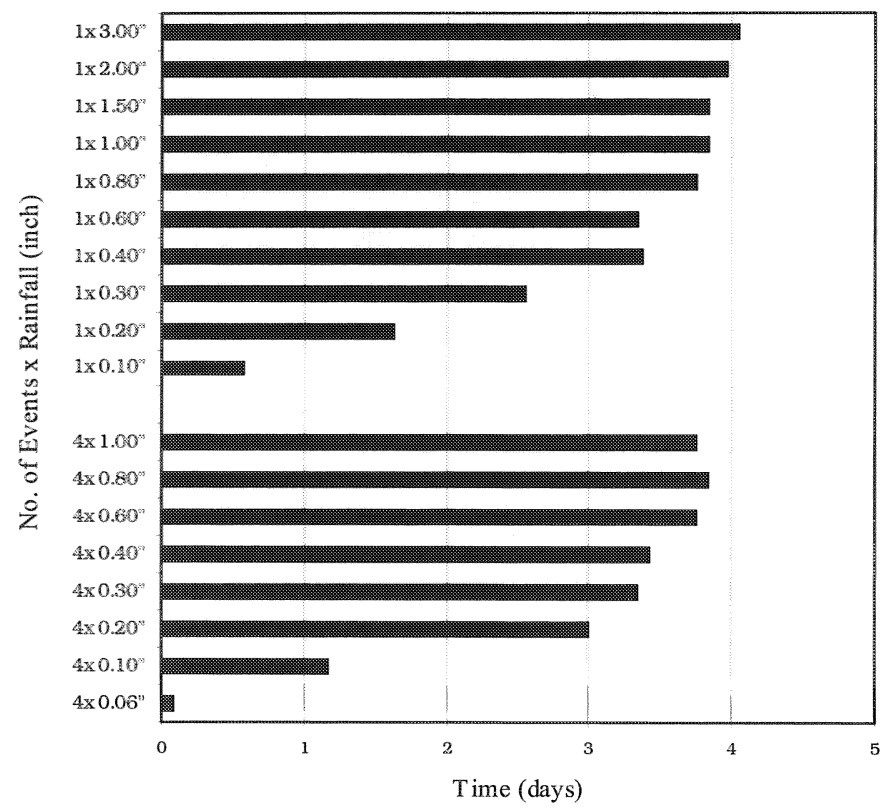

Figure 17.3 Time required for system to return to dry weather flow conditions following end of rainfall event. 
For multiple events, the time for the system to recover from a single event of the same size increases. For instance, the time to recover from a 0.30 -inch $(7.6 \mathrm{~mm})$ event that happens for $4 \mathrm{~d}$ in a row is over $3 \mathrm{~d}$. In contrast, the time to recover is less than $3 \mathrm{~d}$ for a single event of the same size. This result shows the need to account for prior rainfall in determining selection criteria.

The DWF results given in Figure 17.3 are for flows returning to within $2 \%$ of base DWF rates. Figure 17.4 shows the time for flows to return to within $1 \%, 2 \%$, and $5 \%$ of base DWF rates at the WWTP. As would be expected, the time increases as the tolerance range for determining that the system has returned to DWF conditions is decreased. For the 0.8 -inch $(20.3 \mathrm{~mm})$ event, the time ranges from less than $3 \mathrm{~d}$ at $5 \%$ to over $4 \mathrm{~d}$ at $1 \%$.

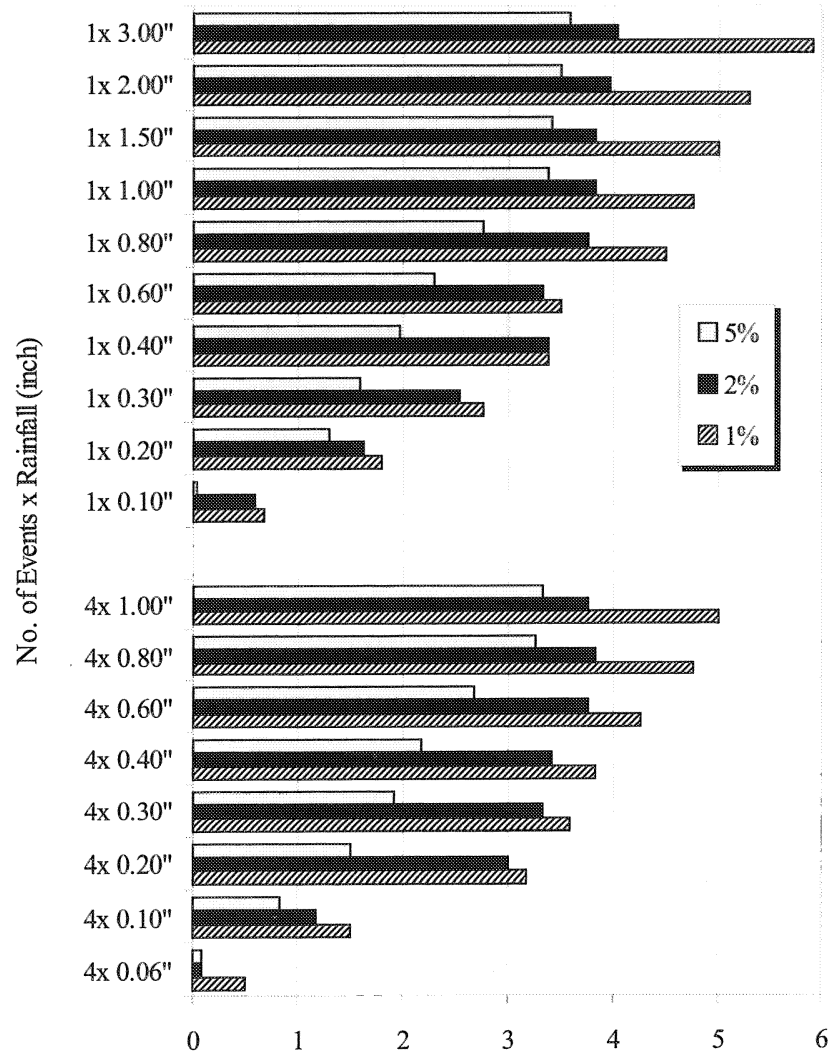

Time to return to within 1,2 or $5 \%$ of DWF rate at WWTP (days)

Figure 17.4 Sensitivity of results to selected tolerance. 
Using a tolerance of $2 \%$ is considered appropriate as that tolerance level would equal or exceed the accuracy of the meters collecting the flow data. In addition, use of a tighter tolerance of $1 \%$ or even less would excessively reduce the DWF data set that could be used in the flow balance analysis.

\subsubsection{Season Impact}

As mentioned previously, the GDRSS model is configured to represent seasonal variation in both DWF and RDI/I response. The simulations described in the previous subsection were performed for the month of April, which represents the highest DWF month and the higher response season for RDI/I. Additional simulations were performed to review the impact of seasonal variation in these parameters on the model results. The model was configured for June and October months to cover an average and low DWF month, respectively, and to cover low (growth) and average (transition) I/I months, respectively. The 1-inch event was selected for these simulations. The results presented in Figure 17.5 show that the time to return to DWF conditions decreases from over $3 \mathrm{~d}$ to less than $3 \mathrm{~d}$ between April and October.

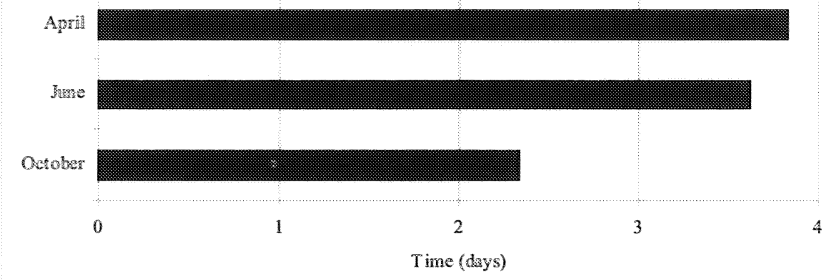

Figure 17.5 Impact of season on time required for system to return to dry weather flow conditions.

\subsubsection{Initial Infiltration Impact}

The initial infiltration can be varied to represent various antecedent conditions. For all criteria simulations, the infiltration rate was set at an average condition value of 0.83 inches $(210 \mathrm{~mm})$ per $\mathrm{h}$ (iph), which is considered representative for average antecedent conditions as discussed. A 1-inch $(254 \mathrm{~mm})$ event was used to assess the impact of increasing the infiltration rate in the results. As can be seen in Figure 17.6, the change in the time required for the system to return to dry weather flow conditions is quite small, on the order of 2 to $3 \mathrm{~h}$. 


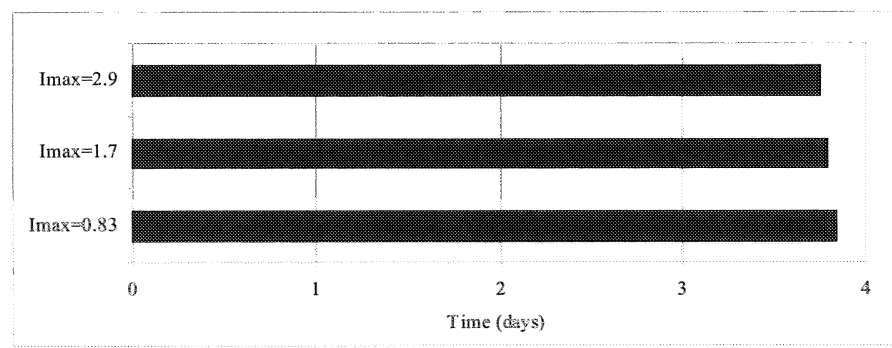

Figure 17.6 Impact of initial infiltration on time required for dry weather flow conditions.

\subsection{Flow Balance Data Selection Criteria}

The rainfall-based DWF data selection criteria are defined in terms of the time required for the system to return to DWF conditions following a rainfall event. An equation was fitted to the data in Figure 17.3 to represent the time to return to DWF conditions as a function of the rainfall amount for a single event. A chart showing this relationship is shown in Figure 17.7.

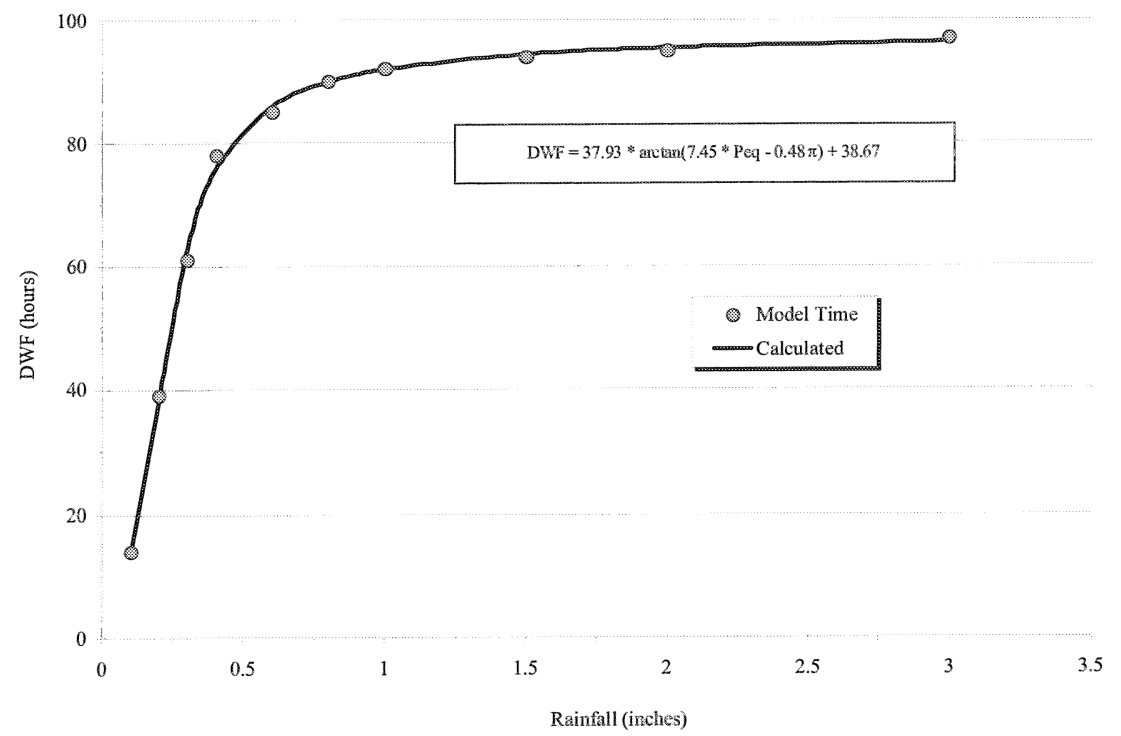

Figure 17.7. Time to return to DWF conditions criteria equation. 
Twenty additional series of non-uniform (temporal) events were simulated and the time to DWF was determined. A complete summary of the rainfall amounts of all single and multiple storm events simulated and their respective time to DWF are shown in Table 17.5.

Table 17.5 Rainfall event simulations.

\begin{tabular}{|c|c|c|c|c|c|}
\hline $\begin{array}{c}\mathrm{P} 4 \\
\text { (inches) }\end{array}$ & $\begin{array}{c}\text { P3 } \\
\text { (inches) }\end{array}$ & $\begin{array}{c}\text { P2 } \\
\text { (inches) }\end{array}$ & $\begin{array}{c}\mathrm{Pp} \\
\text { (inches) }\end{array}$ & $\begin{array}{c}\text { Peq } \\
\text { (inches) }\end{array}$ & $\begin{array}{c}\text { Time to DWF } \\
\text { (hours) }\end{array}$ \\
\hline 0 & 0 & 0 & 0.1 & 0.1 & 14 \\
\hline 0 & 0 & 0.1 & 0.1 & 0.14 & 24 \\
\hline 0 & 0.1 & 0 & 0.1 & 0.144 & 25 \\
\hline 0.1 & 0.2 & 0.1 & 0.1 & 0.152 & 27 \\
\hline 0.1 & 0.1 & 0.1 & 0.1 & 0.156 & 28 \\
\hline 0.1 & 0.1 & 0.2 & 0.1 & 0.168 & 31 \\
\hline 0 & 0 & 0 & 0.2 & 0.2 & 39 \\
\hline 0.8 & 0.1 & 0.1 & 0.1 & 0.2409 & 48 \\
\hline 0.1 & 0.1 & 0.3 & 0.1 & 0.246 & 49 \\
\hline 0.1 & 0.4 & 0.1 & 0.1 & 0.273 & 55 \\
\hline 0.1 & 0.8 & 0.1 & 0.1 & 0.2909 & 59 \\
\hline 0 & 0 & 0 & 0.3 & 0.3 & 61 \\
\hline 0.3 & 0.4 & 0.2 & 0.1 & 0.3294 & 66 \\
\hline 0.4 & 0.3 & 0.2 & 0.1 & 0.3294 & 66 \\
\hline 0.1 & 0.1 & 0.4 & 0.1 & 0.3353 & 67 \\
\hline 0.3 & 0.2 & 0.4 & 0.1 & 0.3353 & 67 \\
\hline 0.2 & 0.2 & 0.2 & 0.2 & 0.34117 & 68 \\
\hline 0.3 & 0.8 & 0.2 & 0.1 & 0.34706 & 69 \\
\hline 0.1 & 0.1 & 0.6 & 0.1 & 0.347 & 69 \\
\hline 0.1 & 0.1 & 0.7 & 0.1 & 0.359 & 71 \\
\hline 0.1 & 0.1 & 0.8 & 0.1 & 0.37058 & 73 \\
\hline 0.3 & 0.2 & 0.8 & 0.1 & 0.37058 & 73 \\
\hline 0 & 0 & 0 & 0.4 & 0.4 & 78 \\
\hline 0.2 & 0.8 & 0.2 & 0.2 & 0.42857 & 79 \\
\hline 0.3 & 0.3 & 0.3 & 0.3 & 0.457 & 80 \\
\hline 0.1 & 0.2 & 0.3 & 0.4 & 0.4857 & 81 \\
\hline 0.2 & 0.2 & 0.8 & 0.2 & 0.5429 & 83 \\
\hline 0.4 & 0.4 & 0.4 & 0.4 & 0.6 & 85 \\
\hline 0 & 0 & 0 & 0.6 & 0.6 & 85 \\
\hline 0.6 & 0.6 & 0.6 & 0.6 & 0.8 & 90 \\
\hline 0 & 0 & 0 & 0.8 & 0.8 & 90 \\
\hline 0.8 & 0.8 & 0.8 & 0.8 & 1 & 92 \\
\hline 0 & 0 & 0 & 1 & 1 & 92 \\
\hline 1 & 1 & 1 & 1 & 1.25 & 93 \\
\hline
\end{tabular}

For each simulation, the time for the system to return to DWF condition was determined as previously stated. The selection criteria equation shown in Figure 17.7 was then used to back-calculate the equivalent single-rainfall amount that would result in the same time needed to reach DWF conditions. Once this equivalent single-rainfall amount was determined for each simulation, two least-squares linear equations were fitted to the data. One equation was for 


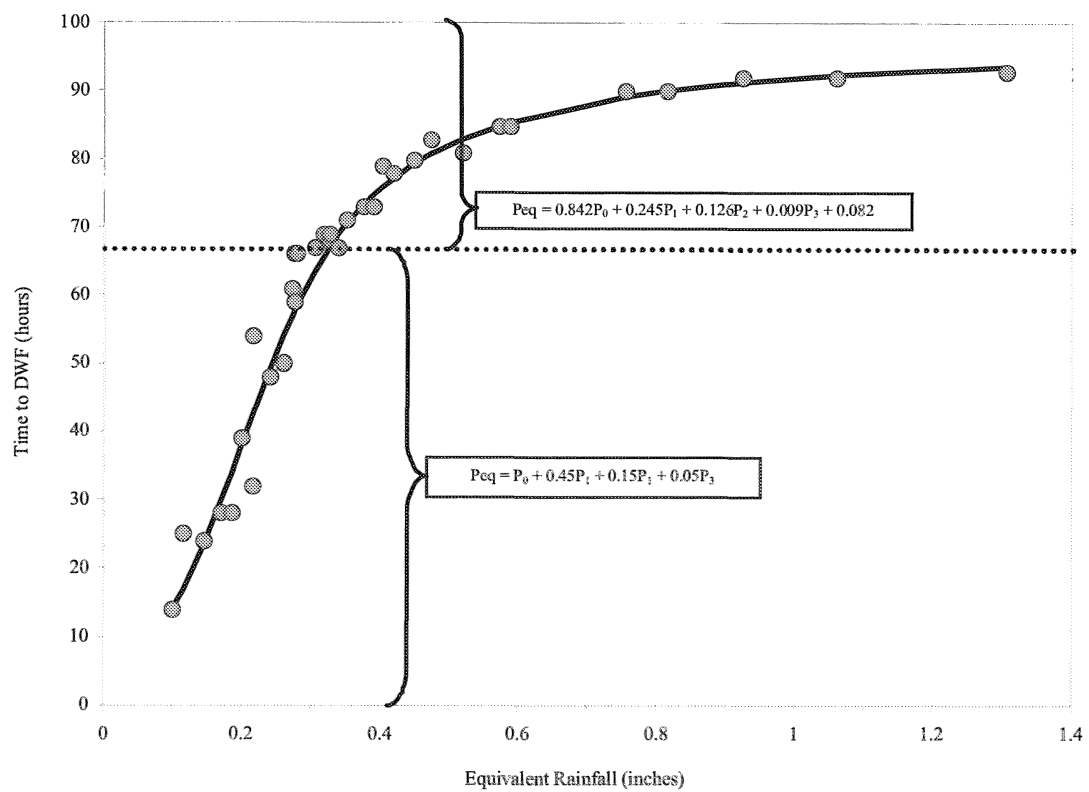

Figure 17.8 Single equivalent rainfall for multiple day events.

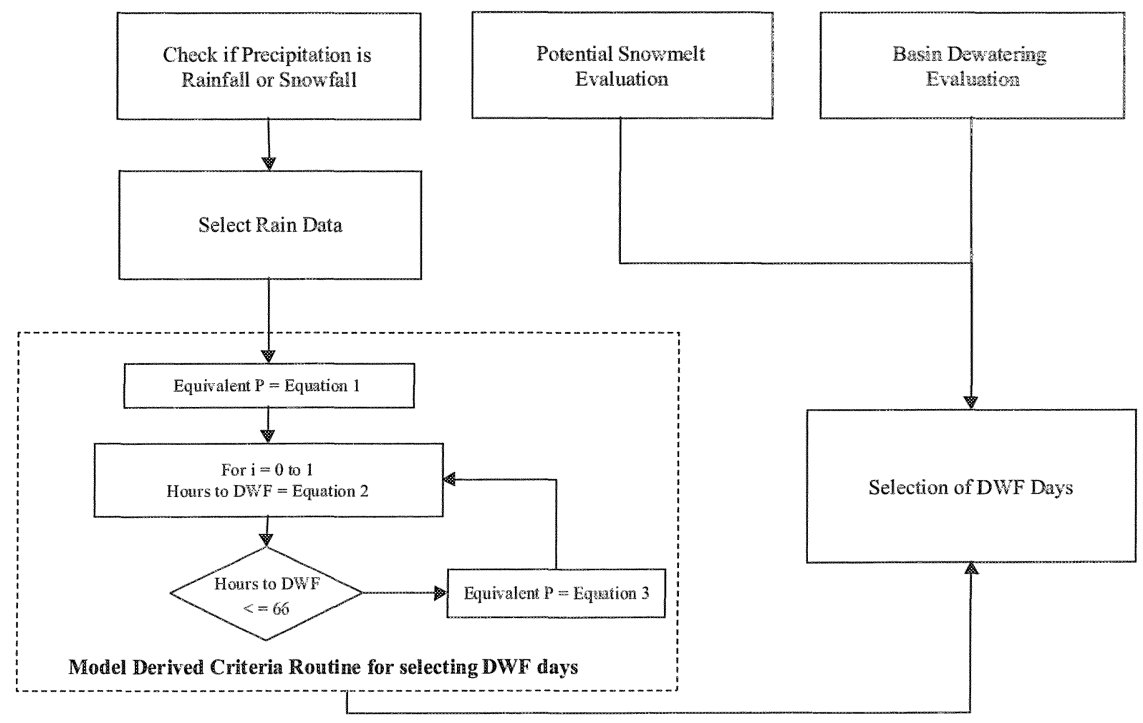

Equation 1: Equivalent $\mathrm{P}=\mathrm{P}_{\mathrm{n}} * 0.842+\mathrm{P}_{\mathrm{n}-1} * 0.245+\mathrm{P}_{\mathrm{n}-2} * 0.126+\mathrm{P}_{\mathrm{n}-4} * 0.082$

Equation 2: Hours to dry weather flow (DWF): $37.93^{*}$ AreTan $(7.45 *$ Equivalent $\mathrm{P}-0.48 * \mathrm{PI})+38.47$

Equation 3: New Equivalent $\mathrm{P}=\mathrm{P}_{\mathrm{n}}+\mathrm{P}_{\mathrm{n}-1} * 0.45+\mathrm{P}_{\mathrm{n}-\mathrm{2}^{*}} * 0.15+\mathrm{P}_{\mathrm{n}-3} * 0.05$

Note: $P_{n}=$ Average precipitation from top fire gages on nth day

Figure 17.9 Simplified flowchart for the selection of DWF days. 
an equivalent rainfall amount that would produce greater than $65 \mathrm{~h}$ to DWF conditions and the other equation for an equivalent rainfall amount that would produce less than $65 \mathrm{~h}$ to DWF conditions. Model results are compared to the two equations in Figure 17.8

The algorithm for the application of the above relationships in the flow balance analysis is shown in Figure 17.9. This figure also includes consideration for snowmelt and/or basin dewatering, which are tracked separately in addition to the rainfall-based criteria described in this chapter.

Using this algorithm, up to $4 \mathrm{~d}$ of rainfall can be converted to an equivalent 1-d rainfall amount to determine the time needed for the system to return to DWF conditions. The calculated time to DWF can then be used to eliminate data from the start to the end of a storm event. Any flow data collected after this time period is considered to be appropriate for the flow balance analysis.

\subsection{Limitations and Assumptions}

The following limitations and assumptions are identified for the selection criteria:

- the DWF data selection criteria given above uses the average of the highest five daily rainfall depths from rain gages located in the tributary areas for determining appropriate times to perform the flow balance analysis;

- the average rainfall amount of the ral event (five highest gages) will be comparable to a uniform event simulated;

- time to DWF as defined herein does not include any basin dewatering of the system operations that may delay the release of wet weather flow into the system following a storm event;

- the complete data selection criteria protocol assumes that snowmelt can be translated into an equivalent rainfall event; and

- the criteria were established for system flows returning to within $2 \%$ of base DWF.

\subsection{Conclusions}

The Greater Detroit Regional Sewer System model was used to refine the rainfall-based criteria for selection of flow data being used in a flow balance analysis. The model was specifically used to determine the time required for the system to return to dry weather flow conditions after one or a series of rainfall events. Relationships were developed that represent time-to-dry as a function 
of the rainfall amount of single rainfall events. In addition, relationships were developed to represent multiple-day rainfall events by a single-day equivalent rainfall event. These relationships are a key component of the overall data selection for the flow balance, and provide an objective approach to characterizing DWF in the DWSD collection system.

\section{Acknowledgments}

We acknowledge Sree Madichetty (Wade-Trim) for support and refinement of the application of the flow balance data selection criteria.

\section{References}

10Brooks Software. 1995. Model Turbo View-Extran, Users Manual, Version 3.11, 3744 W. Huron River Drive, Suite 200, Ann Arbor, Michigan 48103

City of Detroit. 1996. Long Term CSO Control Plan for the Detroit and Rouge Rivers. Consultant Services Contract: CS-1158, DWSD, Detroit, Michigan.

Huber, W.C. and Dickinson, R.E. 1988. Storm Water Management Model, Version 4: User's Manual. Cooperative Agreement CR-811607. United States Environmental Protection Agency. Athens, Georgia. 569 pp.

TenBroek, M.J., G. Fujita, P. Brink, B.J. Sherman and D. White. 1999. "Detroit Water and Sewerage Department Model Extensions and Project Overview." Journal of Water Management Modeling R204-11. doi: 10.14796/JWMM.R204-11. 
